\title{
OUTCOME OF AUTOLOGOUS BONE MARROW INJECTION AT FRACTURE SITE IN DELAYED UNION OF LONG BONE: A SERIES OF 10 CASES
}

\author{
Rajendraprasad Butala1, Abhay Agarwal2, Ravindra G. Khedekar ${ }^{3}$, Nabokrishna Gohain 4 , Amit Grover5, Abhinav Garg6, \\ Sunirmal Kumar Mukherjee ${ }^{7}$ \\ ${ }^{1}$ Associate Professor, Department of Orthopaedics, Dr. D. Y. Patil Medical College, Navi Mumbai. \\ ${ }^{2}$ Registrar, Department of Orthopaedics, Dr. D. Y. Patil Medical College, Navi Mumbai. \\ 3 Professor and Head of Unit, Department of Orthopaedics, Dr. D. Y. Patil Medical College, Navi Mumbai. \\ ${ }^{4}$ Registrar, Department of Orthopaedics, Dr. D. Y. Patil Medical College, Navi Mumbai. \\ ${ }^{5}$ Registrar, Department of Orthopaedics, Dr. D. Y. Patil Medical College, Navi Mumbai. \\ ${ }^{6}$ Registrar, Department of Orthopaedics, Dr. D. Y. Patil Medical College, Navi Mumbai. \\ ${ }^{7}$ Assistant Professor, Department of Orthopaedics, Dr. D. Y. Patil Medical College, Navi Mumbai.
}

\section{ABSTRACT}

US FDA ${ }^{1}$ states non-union as when minimum of 9 months has elapsed since injury and fracture shows no progressive signs of healing for 3 months. However, there is no consensus regarding time period for delayed union. Various new non-operative or percutaneous methods for treating delayed union and non-union have been described like stem cell therapy, ${ }^{2}$ bone morphogenic protein-2 injection ${ }^{3}$ at fracture site, platelet rich plasma. ${ }^{4}$ In our study, bone marrow injection were done at fracture site in cases of delayed union, 12 weeks postoperative period for tibia, humerus and femur fracture, and at 8 weeks for both bone forearm fracture. A total of 10 patients were selected over a period of 2 years at Dr. D. Y. Patil Hospital, Navi Mumbai. Post injection, the limb was immobilized for 7 days followed by joint mobilization and weight bearing as tolerated. Out of 10 patients, 9 showed signs of union at 12 weeks post injection with one tibia shaft fracture, which failed to unite and required revision surgery. We recommend bone marrow injection for delayed union as a simple and cost-effective technique with good results.

\section{KEYWORDS}

Autologous Bone Marrow Injection, Delayed Union.

HOW TO CITE THIS ARTICLE: Butala R, Agarwal A, Khedekar RG, et al. Outcome of autologous bone marrow injection at fracture site in delayed union of long bone: a series of 10 cases. J. Evolution Med. Dent. Sci. 2016;5(56):3841-3843, DOI: $10.14260 /$ jemds/2016/879

\section{INTRODUCTION}

Long bone diaphyseal fractures can be treated using the principle of relative stability using locking plates or nailing. Humerus and radius-ulna can be fixed using compression plating being non-weight bearing bones. Approximately $5 \%$ of all long bone fracture result in non-union and even more in delayed union. The reported incidence of non-union of femoral shaft fracture is less than $1 \%$ following nailing that tibia shaft fracture is $5-10 \%$, humerus shaft fracture $5 \%$ following closed treatment ${ }^{5}$ and radius ulna is from 2 to $10 \%$.

The aim of this study is to recognise clinical and radiological signs of aseptic delayed union and subsequent outcome following bone marrow injection at fracture site.

\section{MATERIAL AND METHODS}

In our study, delayed union was defined as absence of clinical and radiological signs of union after 12 weeks of stable fracture fixation without any sign of infection.

Total 10 patients were selected over a period of 2 years between January 2012 to June 2015 who were operated for long bone diaphyseal fracture and had persistent pain at fracture site or on joint mobilization and unaided weight bearing with no radiological sign of secondary (Callus) or primary bone healing after 12 weeks from surgery.

Financial or Other, Competing Interest: None.

Submission 29-03-2016, Peer Review 24-04-2016,

Acceptance 29-04-2016, Published 13-07-2016.

Corresponding Author:

Dr. Sunirmal Kumar Mukherjee,

\#702, Torino, South Avenue,

Hiranandani Gardens, Powai,

Mumbai-400076,

Maharashtra, India.

E-mail: sunmukherjee1987@yahoo.com

DOI: $10.14260 /$ jemds $/ 2016 / 879$

\section{Inclusion Criteria}

- Age $>18$ year age.

- Patients operated for shaft fracture long bone with no sign of union at 8-12 weeks follow up.

- No sign of infection.

\section{Exclusion Criteria}

- Fractures not operated with stable fixation. (Excess movement at fracture site).

- Osteoporotic bone/pathological fracture.

- Delayed union resulting due to infection at fracture site.

- Cachexic patient/medical comorbidities resulting in poor healing at fracture site.

\section{PROCEDURE}

Patients selected were given spinal anaesthesia.

After parts preparation, 18G bone marrow aspiration needle was used for aspiration from iliac crest $2 \mathrm{~cm}$ posterior to anterior superior iliac spine.

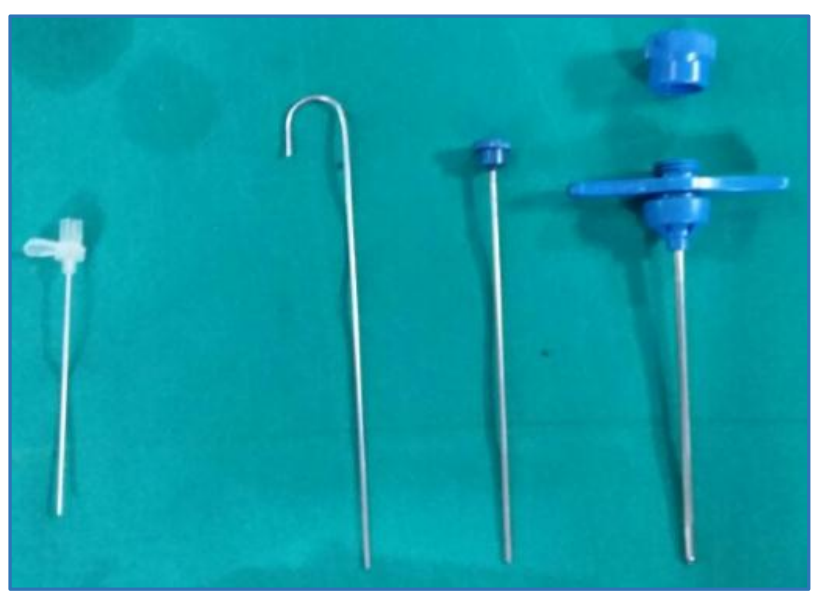

Fig. 1: Bone Marrow Aspiration Needle 


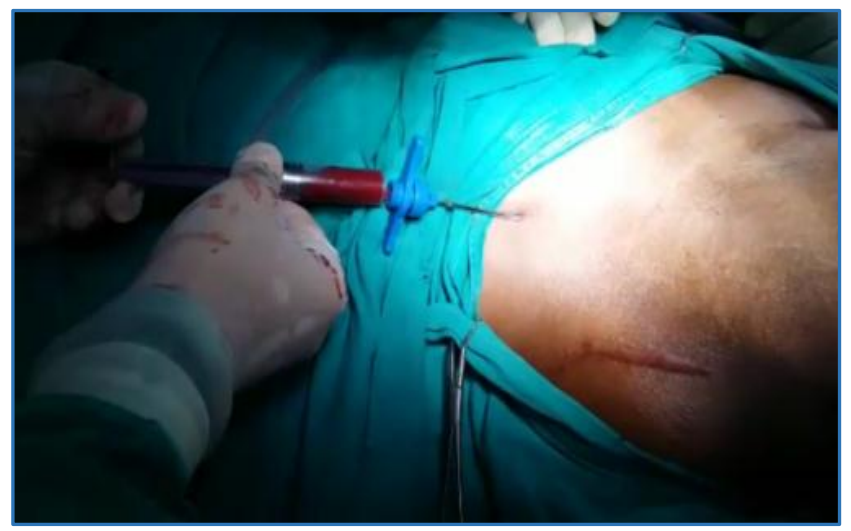

Fig. 2: Bone Marrow Aspiration from Iliac Crest

A total of 15 cc bone marrow was aspirated and was inserted into fracture site under fluoroscopic guidance. Special care was taken to follow a zig-zag tract while introducing the needle through the soft tissue before reaching the fracture site.
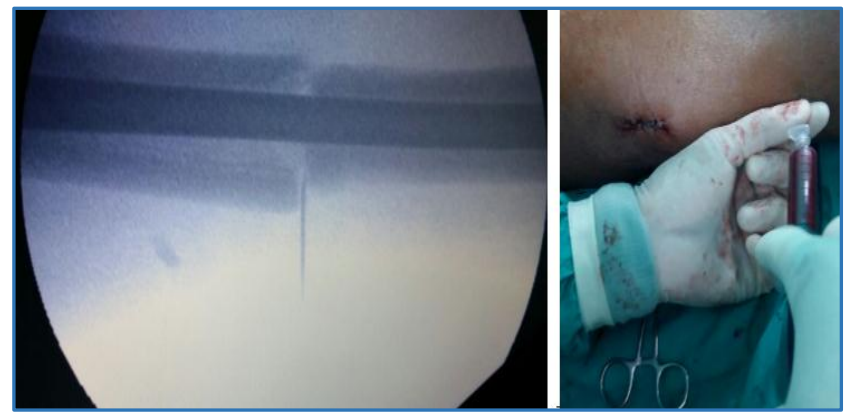

Fig. 3: Needle Introduction at Fracture Site

The injection site was sealed by tincture benzoate cotton plug.

Postoperatively, limb was immobilized for 5 days followed by active mobilization depending on pain tolerance.

Patients were followed up every 6 weeks for clinical signs of union and check $x$-rays were taken.

\section{RESULTS}

In our study, there were 3 femur fractures, 3 tibia fractures, 3 humerus fractures, and 1 radius fracture. All the fractures were operated with intramedullary interlocking nail for tibia, femur, and humerus and titanium elastic nail for radius-ulna fracture. There were no radiological signs of callus formation at 8 weeks follow-up x-ray in these patients along with tenderness at fracture site on palpation and had painful mobilization/weight bearing.

Bone marrow injection were done at 12 weeks postoperative period for tibia, humerus, and femur fracture and at 8 weeks for both bone forearm fracture.

Following bone marrow injection, 9 fractures showed callus formation at fracture site at 12 weeks follow-up with clinical signs of union i.e. lack of tenderness at fracture site and painless joint mobilization and unaided weight bearing walk.

One tibia fracture went into atrophic non-union for which excision of sclerotic bone ends, exchange nailing with iliac crest bone grafting was done.

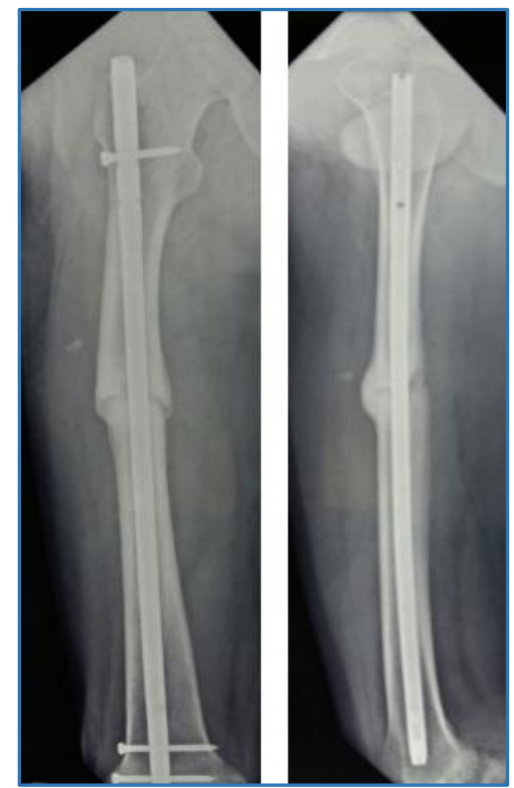

Fig. 4: 12 Week Follow-Up Post Marrow Injection

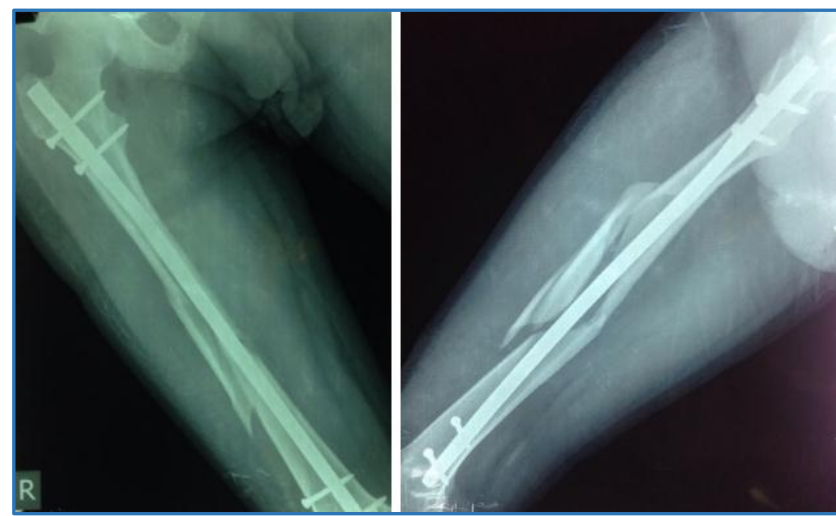

Fig. 5: 12 Week Postop

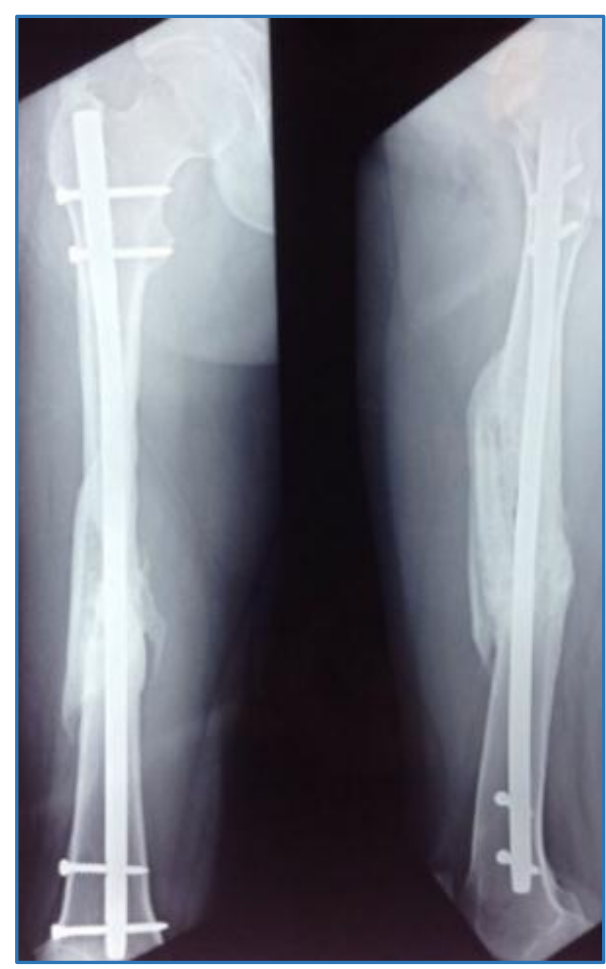

Fig. 6: 6 Month Postop (After Bone Marrow Injection) 


\section{DISCUSSION}

US FDA ${ }^{1}$ states non-union as when minimum of 9 months has elapsed since injury and fracture shows no progressive signs of healing for 3 months. However, there is no consensus regarding time period for delayed union. In our study, we have taken into consideration a period of 8 to 12 weeks to label as delayed union if the fracture showed no sign of healing. Various new non-operative or percutaneous methods for treating delayed union and non-union have been described like stem cell therapy, ${ }^{2}$ bone morphogenic protein- 2 injection ${ }^{3}$ at fracture site, platelet rich plasma. ${ }^{4}$ However, the above methods are costly and not easily available. Bone marrow aspiration and injection on the other hand is simple procedure, cheap, and technically easy to perform with good results.

The only drawbacks, which should be highlighted are regarding patient selection, which require marrow injection as there is no consensus regarding defining delayed union. Also, there is no method to know whether the bone marrow injected is retained at the fracture site and for how long.

Multiple studies by R Sim, ${ }^{6} \mathrm{R}$ Bhargava et al ${ }^{7}$ Siwach RC et $\mathrm{al}^{8}$ show good results of autologous bone marrow aspiration not only in delayed union, but also in selected cases of nonunion.

From our experience, we recommend bone marrow injection in selected cases of delayed union with good results.

\section{REFERENCES}

1. Terry Canale S, James H. Beaty-Campbell's Operative Orthopaedics 12 th edition. chapter 59, Vol 3:pg 2982.

2. Gomez-Barrena E, Rosset P, Lozano D, et al. Bone fracture healing: cell therapy in delayed unions and non-unions. Bone 2015;70:93-101.

3. Saito N, Okada T, Horiuchi H, et al. Local bone formation by injection of recombinant human bone morphogenetic protein-2 contained in polymer carriers. Bone 2003;32(4):381-6.

4. Roberto Civinini, Armando Macera, Lorenzo Nistri, et al. The use of autologous blood-derived growth factors in bone regeneration. Clin Cases Miner Bone Metab 2011;8(1):25-31.

5. Cadet ER, Yin B, Schulz B, et al. Proximal humerus and humerus shaft non-union. J Am Acad Orthop Surg 2013;21(9):538-47. doi: 10.5435/JAAOS-21-09-538.

6. Sim R, Liang TS, Tay BK. Autologous marrow injection in the treatment of delayed and non-union in long bones. Singapore Med J 1993;34(5):412-7.

7. Rakesh Bhargava, Sankhla SS, Anil Gupta, et al. Percutaneous autologous bone marrow injection in the treatment of delayed or non-union. Indian J Orthop 2007;41(1):67-71.

8. Siwach RC, Sangwan SS, Singh R, et al. Role of percutaneous bone marrow grafting in delayed unions, non-unions and poor regenerates. Indian J Med Sci 2001;55(6):326-36. 